\title{
Composição florística, estrutura e biomassa de plantas arbóreas/arbustivas da Caatinga
}

Objetivou-se determinar a composição florística e estrutura fitossociológica de um fragmento de Caatinga em regeneração e estimar o estoque de biomassa nas plantas arbóreo/arbustivas, a fim de determinar seu potencial energético. Conduziu-se o trabalho na Fazenda Experimental Piroás (FEP), da Universidade da Integração Internacional da Lusofonia Afro-Brasileira (UNILAB), Redenção, Ceará. Na composição florística das plantas adotou-se o método de quadrantes. Estimouse os parâmetros fitossociológicos das espécies: densidade absoluta (DA) e relativa (DR), frequência absoluta (FA) e relativa (FR), dominância absoluta (DoA) e relativa (DoR) e índice de valor de importância (IVI). A biomassa aérea total de cada espécie foi estimada utilizando equações alométicas. Observou-se 15 famílias e 27 espécies de plantas. A família Fabaceae destacou-se das demais, com 9 espécies. Os maiores números de indivíduos e IVI foram da Piptadenia stipulacea Mimosa caesalpiniifolia e Bauhinia cheilantha. O estoque de biomassa das espécies refletiu o número de indivíduos e diâmetro dos mesmos, assim, T. gardneriana apresentou maior biomassa, devido maior diâmetro, seguida de M. Caesalpiniifolia e P. stipulacea, devido aos maiores números de indivíduos. Estas três espécies contribuem para a produção de biomassa do fragmento de Caatinga, representando possíveis alternativas a serem utilizadas como fonte de energia.

Palavras-chave: Biomassa arbóreas; Piptadenia stipulacea; Biodiversidade; Semiárido.

\section{Floristic composition, structure and biomass of plant of trees/arbustives from the Caatinga}

The objective of this study was to determine the floristic composition and phytosociological structure of a regenerating Caatinga fragment and to estimate the biomass stock in the tree/shrub in order to determine its energy potential. The work was conducted at Piroás Experimental Farm (FEP), University of International Integration of Afro-Brazilian Lusophony (UNILAB), Redenção, Ceará. The floristic composition of the plants adopted the quadrant method. The phytosociologica parameters of the species were estimated: absolute (AD) and relative density (DR), absolute (AF) and relative frequency (RF), absolute (DoA) and relative dominance (DoR) and importance value index (IVI). The total aerial biomass of each species was estimated using allometric equations. Fifteen families and 27 plant species were observed. The Fabaceae family stood out from the others, with 9 species. The largest numbers of individuals and IVI were from Piptadenia stipulacea, Mimosa caesalpiniifolia and Bauhinia cheilantha. The biomass stock of the species reflected the number of individuals and their diameter, thus T. gardneriana presented higher biomass due to larger diameter, followed by M. Caesalpiniifolia and P. stipulacea, due to the higher number of individuals. These three species contribute to the biomass production of the Caatinga fragment, representing possible alternatives to be used as an energy source.

Keywords: Arboreal biomass; Piptadenia stipulacea; Biodiversity; Semiarid.

Topic: Uso Sustentável da Biodiversidade

Reviewed anonymously in the process of blind peer
Received: 05/12/2020

Approved: 20/02/2021
Maria Ivanilda de Aguiar (ID)

Universidade da Integração Internacional da Lusofonia Afro Brasileira, Brasil http://lattes.cnpq.br/5455983813192128 http://orcid.org/0000-0002-6147-2621 ivanilda@unilab.edu.br

Olienaide Ribeiro de Oliveira Pinto (i) Universidade da Integração Internacional da Lusofonia Afro Brasileira, Brasil http://lattes.cnpq.br/8216617581480616 http://orcid.org/0000-0002-8333-3665 agron.olienaide@gmail.com

\section{Edson Cardoso Lopes}

Universidade da Integração Internacional da Lusofonia Afro Brasileira, Brasil http://lattes.cnpq.br/9159803053475720 http://orcid.org/0000-0003-0883-9225 edsoncardoso89@hotmail.com

\author{
Elânia Soares de Sena (ic \\ Universidade da Integração Internacional da \\ Lusofonia Afro Brasileira, Brasil \\ http://lattes.cnpq.br/0318579302991102 \\ http://orcid.org/0000-0002-4702-4363 \\ elaniasena35@hotmail.com \\ João Gutermberg Leite Moraes (ic) \\ Universidade da Integração Internacional da \\ Lusofonia Afro Brasileira, Brasil \\ http://lattes.cnpq.br/1063890056906762 \\ http://orcid.org/0000-0002-3340-2191 \\ gutember.moraes@unilab.edu.br \\ Fred Denilson Barbosa da Silva (ib) \\ Universidade da Integração Internacional da \\ Lusofonia Afro Brasileira, Brasil \\ http://lattes.cnpq.br/6158748616979607 \\ http://orcid.org/0000-0002-6365-6045 \\ freddenilson@unilab.edu.br
}

Rafaella da Silva Nogueira (iD)

Universidade da Integração Internacional da Lusofonia Afro Brasileira, Brasil http://lattes.cnpq.br/5709447822168454 http://orcid.org/0000-0001-7540-1173 rafaellanogueira@unilab.edu.b

\section{Juan Carlos Alvarado Alcócer (iD)}

Universidade da Integração Internacional da Lusofonia Afro Brasileira, Brasil http://lattes.cnpq.br/8172187725052094 http://orcid.org/0000-0002-6641-1617 jcalcocer@unilab.edu.br 


\section{INTRODUÇÃO}

A Caatinga possui uma vegetação xerófila, e é um dos biomas mais ameaçados e modificados pela ação antropogênica no Brasil (LIMA JÚNIOR et al., 2014). Este bioma recobria originalmente quase todo o semiárido nordestino, englobando cerca de 1,5 milhão de quilômetros quadrados da região, porém, segundo o Sistema Nacional de Informações Florestais, a área de Caatinga no Brasil, em 2009, era de apenas 844.453 $\mathrm{km}^{2}$, representando 9,92\% da área territorial do Brasil (BRAND, 2017). Ainda que esse bioma possua espécies endêmicas da fauna e flora, não recebe atenção necessária e vem vivenciando modificações na estrutura vegetal, tanto pelo extrativismo de madeira para confecção de carvão, quanto pela agricultura de subsistência, pecuária extensiva (CAVALCANTI et al., 2009) e mudanças edafoclimáticos. Assim, estudos para diagnosticar e entender as mudanças nas suas fitofisionomia e estrutura são indispensáveis (CAMPOS, 2016).

Ao longo de toda a extensão geográfica esse bioma apresenta ampla variação, tanto no porte e densidade das plantas, quanto em sua composição florística (AMORIM et al., 2005). A redução na cobertura vegetal nativa do semiárido nordestino tem favorecido à degradação dos recursos naturais, à redução da fertilidade do solo e em casos mais extremos à desertificação (LIMA JÚNIOR et al., 2014).

Vários fatores influenciam a variabilidade florística e fisionômica da Caatinga. Os estudos fitossociológicos evidenciam eventuais alterações na estrutura da vegetação, em seus arranjos, em suas interdependências, em seu desenvolvimento e comportamento no fenômeno de sucessão, podendo, assim, fornecer subsídios que promovam ações voltadas a preservação de sua diversidade genética e sua utilização sustentável (CORDEIRO et al., 2013).

A composição fisionômica da vegetação da Caatinga resulta da combinação de vários atributos particulares às espécies, tais como: a densidade, que se refere à relação das quantidades em que cada espécie ocorre por unidade de área; a frequência, que é a forma como estas espécies se distribuem e a dominância que é o espaço que cada uma ocupa (CAMPOS, 2016). O resultado do somatório destes atributos representa o valor de importância, que é o grau de representatividade das espécies e das famílias botânicas num determinado ambiente florestal (RODAL et al., 2013).

A biomassa arbórea/arbustiva, pode ser oriunda das partes vivas das plantas (tronco, galhos, raízes, cascas, sementes e folhagens) ou das mortas (serrapilheira, galhos e troncos caídos) (HIGA et al., 2014). Por meio da quantificação desta biomassa, obtêm-se informações essenciais para atividades econômicas e ambientais, bem como às voltadas para políticas de uso do recurso madeireiro, com a finalidade energética, manejo florestal, estudos relacionados às mudanças climáticas, sequestro de carbono e ciclagem de nutrientes (PALÁCIO, 2011). A estimativa da biomassa é uma medida útil para comparar os atributos estruturais e funcionais das vegetações florestais em várias condições do ambiente, onde têm sido utilizados elementos permanentes para estudos ecológicos, que são usados, por exemplo, medidas de diâmetro, altura, peso do material vegetal das plantas e densidade da madeira (FREITAS et al., 2012).

Nos últimos anos a Caatinga vem sendo estudada, acreditando-se que o compartimento arbustivo/arbóreo possa ser um potencial reservatório de carbono contribuindo no processo de mitigação 
do efeito estufa. Pereira Júnior et al. (2016) verificaram que a floresta tropical seca brasileira foi eficaz em reduzir $\mathrm{CO}_{2}$ na atmosfera, tendo as árvores a maior colaboração para a redução do aquecimento global. Nesse sentido, são necessários estudo que contribuam para o entendimento de como áreas de Caatinga em regeneração proporcionam à vegetação condições de renovação da capacidade produtiva e da regeneração dos ecossistemas florestais da Caatinga. Uma vez que, conhecer a composição florística, a diversidade e a estrutura fitossocilógica da vegetação contribui grandemente para o correto manejo dos ecossistemas, sua recuperação, conservação e uso racional, especialmente diante das mudanças que podem surgir devido ao manejo (VELAZCO et al., 2015).

Portanto, o presente trabalho teve como objetivo determinar a composição florística e estrutura fitossociológica de um fragmento de Caatinga em regeneração, e estimar o estoque de biomassa presente nas plantas arbóreo/arbustivas desta área.

\section{MATERIAIS E MÉTODOS}

O trabalho foi desenvolvido na Fazenda Experimental Piroás (FEP), pertencente à Universidade da Integração Internacional da Lusofonia Afro-Brasileira (UNILAB), situada no município de Redenção, Ceará. O clima da região é tropical quente sub-úmido, com temperaturas médias variando de $26^{\circ}$ a $28^{\circ} \mathrm{C}$ e período chuvas concentrado de janeiro a abril (IPECE, 2017). A vegetação é do tipo Caatinga arbustiva densa e solos do tipo Podzólico Vermelho-Amarelo Eutrófico (IPECE, 2017). Na área do experimento (FEP), a precipitação pluviométrica em 2015 foi de 1228,55 mm e a média anual dos anos 2014 a 2017 foi de 1221,99 mm, distribuída principalmente entre os meses de janeiro a junho (Figura 1).

O levantamento das espécies arbóreas/arbustivas foi realizado em uma área da FEP, composta por um fragmento de Caatinga em regeneração há aproximadamente seis anos, após ter sido utilizada para plantio de culturas anuais em regime de sequeiro.

A FEP, localizada no distrito de Barra Nova (04014'53" S de Latitude, 384'10" W de Longitude), possui área total de 33 hectares, sendo subdividida em áreas onde são realizadas diversas práticas agrícolas de forma didática e experimental, seguindo práticas e princípios agroecológicos. Além das áreas manejadas, a mesma possui área de preservação permanente, reserva legal e áreas com vegetação nativa que podem ser manejadas. Na FEP são mantidas aproximadamente 15 espécies de fruteiras, 30 de flores tropicais, 15 de folhagens e elevada diversidade de espécies nativas.

Para o estudo da composição florística adotou-se o método de quadrantes (COTTAM et al., 1956), que consiste em estabelecer um ponto no meio da vegetação, usando uma haste para marcar este ponto e dividir a área ao redor em quatro quadrantes. Em seguida, mede-se a distância do centro do ponto até a árvore ou arbusto mais próximo em cada quadrante, registrando o indivíduo mais próximo.

Neste estudo, os pontos foram estabelecidos sistematicamente ao longo de nove linhas de caminhada no terreno, distante 10 metros $(\mathrm{m})$ entre si. Em cada linha foram definidos oito pontos também distantes 10 metros entre si, formando uma malha regular de $10 \mathrm{~m}$ por $10 \mathrm{~m}$, com um total de 72 pontos amostrados (Figura 2), percorrendo uma área total de 0,72 ha. 
O levantamento dos indivíduos foi realizado de agosto a setembro de 2015. Foram amostrados indivíduos lignificados com altura maior ou igual a um metro e diâmetro ao nível do solo (DNS) igual ou superior a três centímetros (RODAL et al., 2013). A identificação dos indivíduos registrados foi realizada por meio de morfologia comparada, usando-se bibliografia especializada e análise das exsicatas do Herbário da UNILAB.

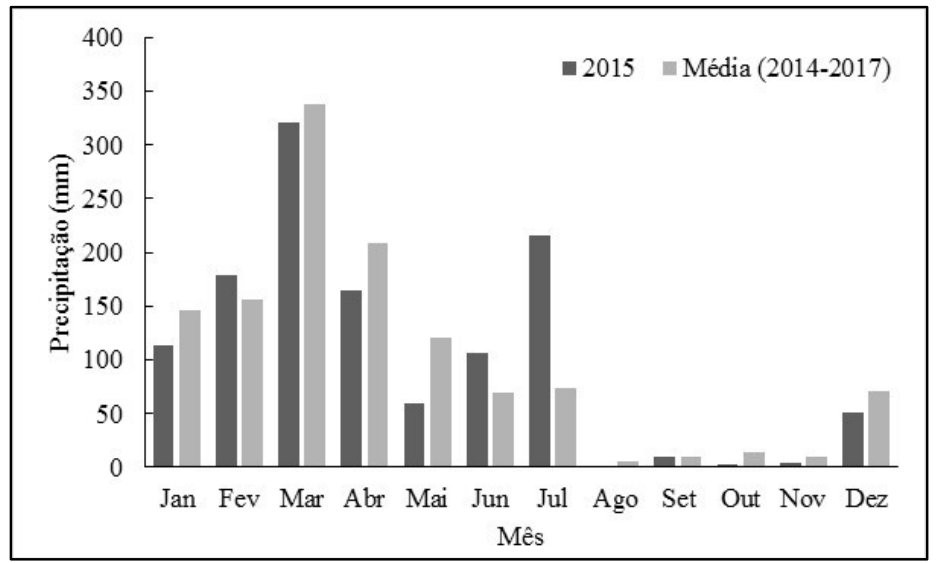

Figura 1: Precipitação pluviométrica do ano de 2015 e média dos últimos quatro anos (2014-2017) na Fazenda Experimental Piroás, Redenção, Ceará.

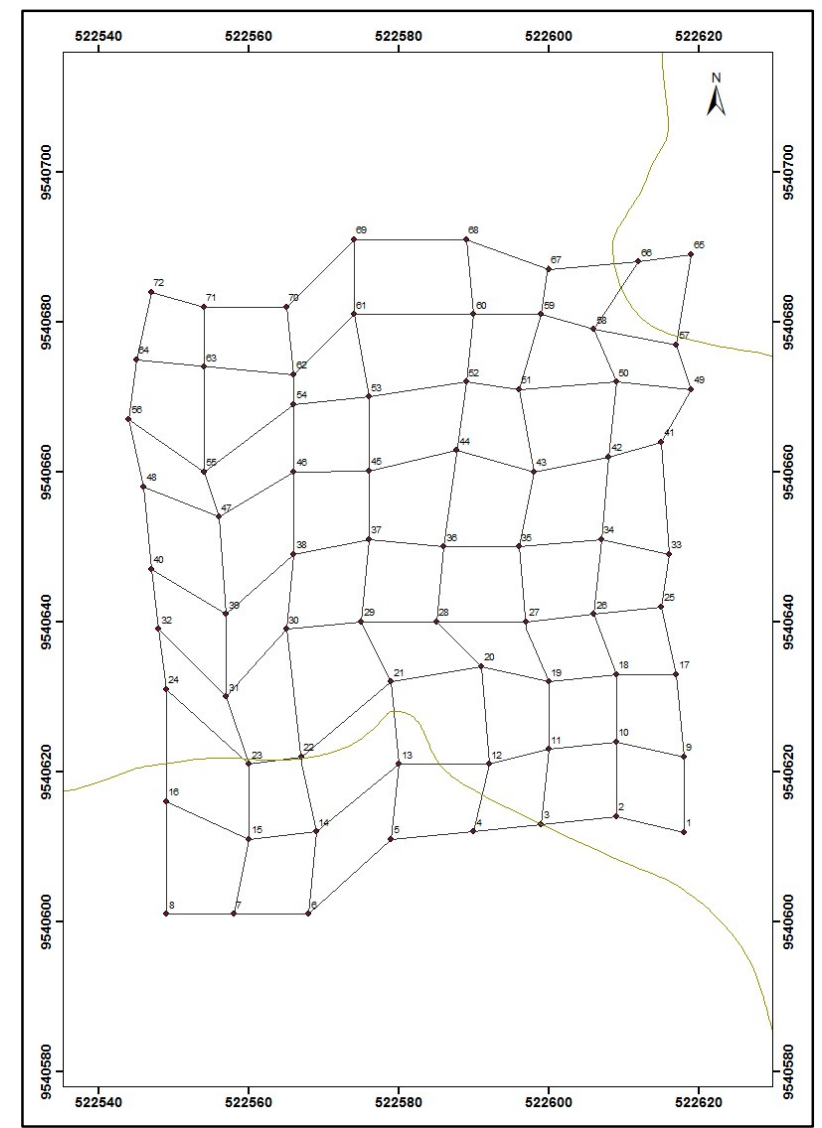

Figura 2: Grid de pontos de amostragem da vegetação arbórea/arbustiva pelo método do quadrante, na Fazenda Experimental Piroás, Redenção, Ceará, 2015.

As famílias botânicas foram organizadas conforme Angiosperm Phylogeny Group III (APG, 2009). Os nomes e classificadores das espécies foram revisados por meio de consultas às listas disponíveis nos sites Tropical. Org, Flora do Brasil e The International Plant Names Index.

Para o estudo dos aspectos estruturais das comunidades arbóreas/arbustivas foram obtidos os 
parâmetros densidades absoluta (DA) e relativa (DR), frequência absoluta (FA) e relativa (FR), dominância absoluta (DoA) e relativa (DoR) e índice de valor de importância (IVI) das espécies, calculadas conforme Felfili et al. (2011).

Os indivíduos do estrato arbóreo/arbustivo foram agrupados em classes de diâmetros (DAS) e alturas. As medidas de diâmetros ao nível do solo (DAS) e ao nível do peito (DNP) foram obtidas por meio de medição da circunferência do caule. Nos indivíduos com caules bifurcados abaixo de 1,3 m, foram medidas todas as ramificações e, posteriormente, calculado um valor único de DAP para cada planta.

A biomassa aérea total de cada espécie foi estimada utilizando equações alométicas, recomendadas por Silva et al. (2008): $B=0,2627^{*} \mathrm{DAP}^{1,9010}$ (para espécies de menor porte) e $\mathrm{B}=0,2368^{*} \mathrm{DAP}^{2,2219}$ (para espécies de maior porte), sendo B: biomassa e DAP: diâmetro ao nível do peito.

\section{RESULTADOS}

Tabela 1: Famílias e espécies encontradas no estrato arbóreo/arbustivo no fragmento de Caatinga em regeneração em Redenção-CE, Brasil, 2015.

\begin{tabular}{|c|c|c|c|}
\hline Família & Espécie & $\mathrm{Ne}$ & $\mathrm{Pe}$ \\
\hline Anacardiaceae & Anacardium occidentale L. & 1 & 1 \\
\hline Annonaceae & Annona muricata $\mathrm{L}$. & 3 & 3 \\
\hline Bixaceae & Bixa orellana $\mathrm{L}$. & 1 & 1 \\
\hline Capparaceae & Capparis cynophallophora L. & 18 & 15 \\
\hline Chrysobalanaceae & Licania rigida Benth & 1 & 1 \\
\hline \multirow[t]{4}{*}{ Euphorbiaceae } & Alchornea sidifolia Mull. Arg. & 1 & 1 \\
\hline & Croton sonderianus Müll. Arg. & 14 & 11 \\
\hline & Jatropha sp. & 3 & 2 \\
\hline & Manihot esculenta Gantz & 1 & 1 \\
\hline \multirow[t]{2}{*}{ Fabaceae - Caesalpinioideae } & Bauhinia cheilantha (Bong.) Steud & 31 & 14 \\
\hline & Delonix regia & 1 & 1 \\
\hline \multirow[t]{7}{*}{ Fabaceae - Mimosoideae. } & Albizia polycephala (Benth.) Killip & 1 & 1 \\
\hline & Mimosa sp & 3 & 3 \\
\hline & Leucaena leucocephala & 4 & 3 \\
\hline & Mimosa arenosa (Willd.) Poir & 26 & 16 \\
\hline & Mimosa caesalpiniifolia Benth & 59 & 29 \\
\hline & Mimosa tenuiflora (Willd.) Poir. & 1 & 1 \\
\hline & Piptadenia stipulacea (Benth.) Ducke & 59 & 36 \\
\hline Malvaceae & Guazuma ulmifolia Lam. & 2 & 2 \\
\hline Meliaceae & Azadirachta indica A. Juss & 11 & 6 \\
\hline Myrsinaceae & Rapanea ferruginea & 2 & 2 \\
\hline Polygonaceae & Triplaris gardneriana Wedd. & 1 & 1 \\
\hline \multirow[t]{2}{*}{ Rhamnaceae } & Rhamnidium elaeocarpum Reissek & 3 & 3 \\
\hline & Ziziphus joazeiro Mart. & 1 & 1 \\
\hline Simaroubaceae & Simarouba amara Aubl. & 1 & 1 \\
\hline Solanaceae & Solanum paniculatum & 1 & 1 \\
\hline Indeterminada 1 & & 9 & 7 \\
\hline
\end{tabular}

Ne: Número de indivíduos observados na espécie $e ;$ Pe: número de unidades amostrais em que a espécie foi observada.

Observou-se 15 famílias e 27 espécies de plantas do componente arbóreo/arbustivo do estrato de Caatinga em regeneração no município de Redenção, Ceará (Tabela 1). A família Fabaceae - Mimosoideae foi que apresentou maior número de espécies e de indivíduos, com destaque para Piptadenia stipulacea (Benth.) Ducke que foi observada em 36 unidades amostrais, totalizando 59 indivíduos. Em seguida, verificou-se a espécie Mimosa caesalpiniifolia Benth que apresentou também 59 indivíduos, registrados em 29 unidades amostrais. Enquanto a espécie Bauhinia cheilantha (Bong.) Steud apontou 31 indivíduos, presentes em 14 unidades amostrais. Posteriormente, a espécies Mimosa arenosa (Willd.) Poir apresentou 26 indivíduos 
observados em 14 unidades amostrais.

Dentre as nove espécies da família Fabaceae, Piptadenia stipulacea foi a que apresentou maior número de indivíduos. Além dessa família, outra que se destacou em relação ao número de indivíduos, foi a Capparaceae com uma espécie (Capparis cynophallophora L.) e 18 indivíduos em 15 unidades amostrais. Logo depois, observou-se a família Euphorbiaceae, com 19 indivíduos distribuídos em 4 espécies, sendo a espécie Croton sondariamos, a mais representativa, com 14 indivíduos observados em 11 unidades amostrais. Observou-se ainda, uma família indeterminada com nove indivíduos observados em sete unidades amostrais.

Os maiores parâmetros fitossociológicos (FA; FR; DA; DR; DoA; DoR e IVI) foram observados nas espécies $P$. stipulacea e $M$. caesalpiniifolia em relação às outras espécies encontradas no estudo. Essas espécies apresentaram maiores frequências relativas (FR) com 39,63\% dos indivíduos. Além das duas espécies citadas, $A$. indica e $M$. arenosa apresentaram elevados valores para os parâmetros fitossociológicos, também se destacando em relação ao índice de valor de importância. O menor IVI foi retratado pela espécie B. orellana L., que também apresentou os menores valores para os outros parâmetros fitossociológicos (Tabela 2).

Tabela 2: Parâmetros fitossociológicos das espécies observadas no estrato arbóreo/arbustivo no fragmento de Caatinga em regeneração em Redenção-CE, Brasil, 2015.

\begin{tabular}{llllllll}
\hline Espécie & $\mathrm{FA}$ & $\mathrm{FR}$ & $\mathrm{DA}$ & $\mathrm{DR}$ & $\mathrm{DoA}$ & $\mathrm{DoR}$ & $\mathrm{IVI}$ \\
\hline A. occidentale & 1,39 & 0,61 & 9,56 & 0,61 & 92,08 & 0,16 & 1,38 \\
A. muricata L. & 4,17 & 1,83 & 28,69 & 1,83 & 1649,91 & 2,79 & 6,45 \\
B. orellana L. & 1,39 & 0,61 & 9,56 & 0,61 & 19,03 & 0,03 & 1,25 \\
C. cynophallophora & 20,83 & 9,15 & 172,14 & 9,15 & 502,60 & 0,85 & 19,14 \\
L. rigida & 1,39 & 0,61 & 9,56 & 0,61 & 3365,36 & 5,70 & 6,92 \\
A. sidifolia & 1,39 & 0,61 & 9,56 & 0,61 & 6,85 & 0,01 & 1,23 \\
C. sonderianus & 15,28 & 6,71 & 133,88 & 6,71 & 716,71 & 1,21 & 14,63 \\
Jatropha sp. & 2,78 & 1,22 & 28,69 & 1,22 & 110,35 & 0,19 & 2,63 \\
M. esculenta & 1,39 & 0,61 & 9,56 & 0,61 & 37,29 & 0,06 & 1,28 \\
B. cheilantha & 19,44 & 8,54 & 296,46 & 8,54 & 2195,44 & 3,72 & 20,79 \\
D. regia & 1,39 & 0,61 & 9,56 & 0,61 & 2649,06 & 4,49 & 5,70 \\
A. polycephala & 1,39 & 0,61 & 9,56 & 0,61 & 4512,00 & 7,64 & 8,86 \\
Mimosa sp & 4,17 & 1,83 & 28,69 & 1,83 & 182,06 & 0,31 & 3,97 \\
L. leucocephala & 4,17 & 1,83 & 38,25 & 1,83 & 300,79 & 0,51 & 4,17 \\
M. arenosa & 22,22 & 9,76 & 248,64 & 9,76 & 3070,39 & 5,20 & 24,71 \\
M. caesalpiniifolia & 40,28 & 17,68 & 516,41 & 17,68 & 12941,70 & 21,91 & 57,28 \\
M. tenuiflora & 1,39 & 0,61 & 9,56 & 0,61 & 149,16 & 0,25 & 1,47 \\
P. stipulacea & 50,00 & 21,95 & 564,22 & 21,95 & 9923,27 & 16,80 & 60,70 \\
G. ulmifolia. & 2,78 & 1,22 & 19,13 & 1,22 & 98,93 & 0,17 & 2,61 \\
A. indica & 8,33 & 3,66 & 105,19 & 3,66 & 10247,88 & 17,35 & 24,67 \\
R. ferruginea & 2,78 & 1,22 & 19,13 & 1,22 & 46,42 & 0,08 & 2,52 \\
T. gardneriana & 1,39 & 0,61 & 9,56 & 0,61 & 1902,51 & 3,22 & 4,44 \\
R. elaeocarpum & 4,17 & 1,83 & 28,69 & 1,83 & 388,11 & 0,66 & 4,32 \\
Z. joazeiro Mart. & 1,39 & 0,61 & 9,56 & 0,61 & 1473,31 & 2,49 & 3,71 \\
S. amara Aubl. & 1,39 & 0,61 & 9,56 & 0,61 & 1610,29 & 2,73 & 3,95 \\
S. paniculatum & 1,39 & 0,61 & 9,56 & 0,61 & 105,97 & 0,18 & 1,40 \\
Indeterminada 1 & 9,72 & 4,27 & 86,07 & 4,27 & 765,94 & 1,30 & 9,83 \\
\hline FA Frequencia absolut
\end{tabular}

FA: Frequência absoluta; FR: Frequência relativa; DA: Densidade absoluta; DR: Densidade Relativa; DoA: Dominância absoluta; DoR: Dominância Relativa; IVA: Índice de Valor de Importância.

As classes de diâmetro (DNP) das plantas arbóreo/arbustivo amostradas no fragmento de Caatinga variaram de $<5 \mathrm{~cm}$ a $<30 \mathrm{~cm}$, sendo que, a maior concentração da distribuição do número de indivíduos ocorreu na classe de diâmetro inferior $(<5 \mathrm{~cm})$, representando 69,14\%. Logo em seguida, observou-se que $16,41 \%$ da distribuição dos indivíduos constituiu-se como a segunda maior classe de diâmetro, variando de 
5 - $10 \mathrm{~cm}$. Já a menor concentração ocorreu na classe de 20 - $25 \mathrm{~cm}$ de diâmetro, com 1,17\% das espécies. As demais classes de diâmetro representaram 13,58\% da distribuição dos indivíduos (Figura 3).

As classes de altura dos indivíduos no fragmento de Caatinga em Redenção diferiram de $<3 \mathrm{~m} \mathrm{a}<9$ m, portanto, a maior distribuição foi observada no intervalo de 3-5 m, representando 36,29\% dos indivíduos estudados. Na sequência, observou-se que 35,91\% das espécies amostradas representaram o intervalo de 5$7 \mathrm{~m}$ e a menor concentração sucedeu na altura $>9 \mathrm{~m}$ (4,25\%), enquanto $27,83 \%$ corresponderam as outras classes de altura das espécies (Figura 4).

A espécie $T$. gardneriana foi a que apresentou maior estoque de biomassa $\left(42,53\right.$ t.ha $\left.^{-1}\right)$, seguida pela M. Caesalpiniifolia $\left(31,46\right.$ t.ha $\left.^{-1}\right)$ e $P$. stipulacea $\left(11,78\right.$ t.ha $\left.{ }^{-1}\right)$. A menor quantidade de biomassa foi verificada na espécie $B$. cheilantha com 0,54 t.ha $^{-1}$ e a soma das demais espécies totalizou 1,57 t.ha ${ }^{-1}$ da quantidade de biomassa do fragmento de Caatinga da FEP (Figura 5).

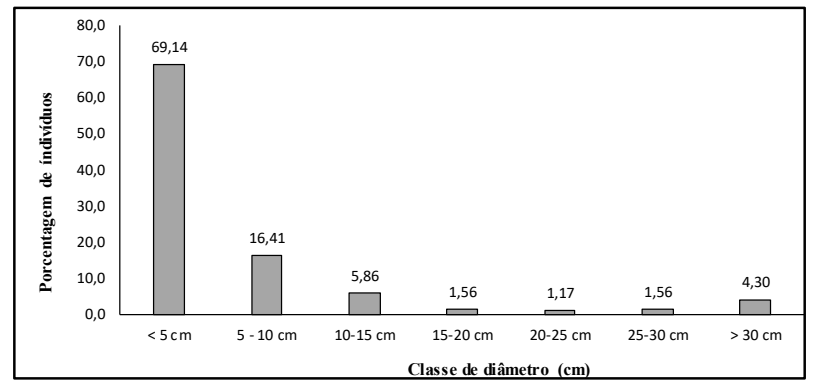

Figura 3: Classes de diâmetros ao nível do peito (DNP) dos indivíduos amostrados no estrato arbóreo/arbustivo no fragmento de Caatinga em regeneração em Redenção, Ceará, Brasil, 2015.

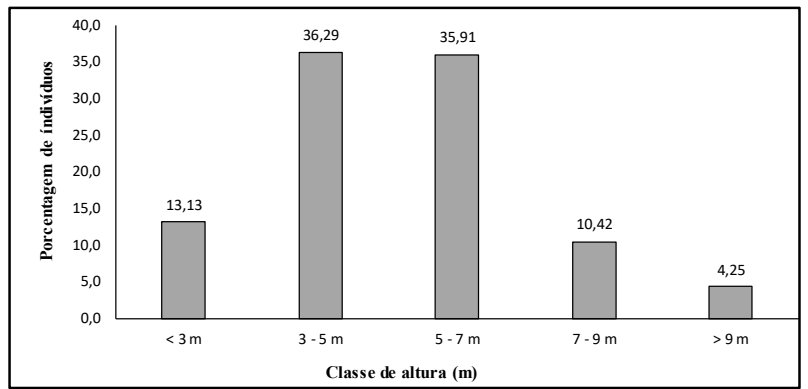

Figura 4: Classes de alturas dos indivíduos amostrados no estrato arbóreo/arbustivo no fragmento de Caatinga em regeneração em Redenção, Ceará, Brasil, 2015.

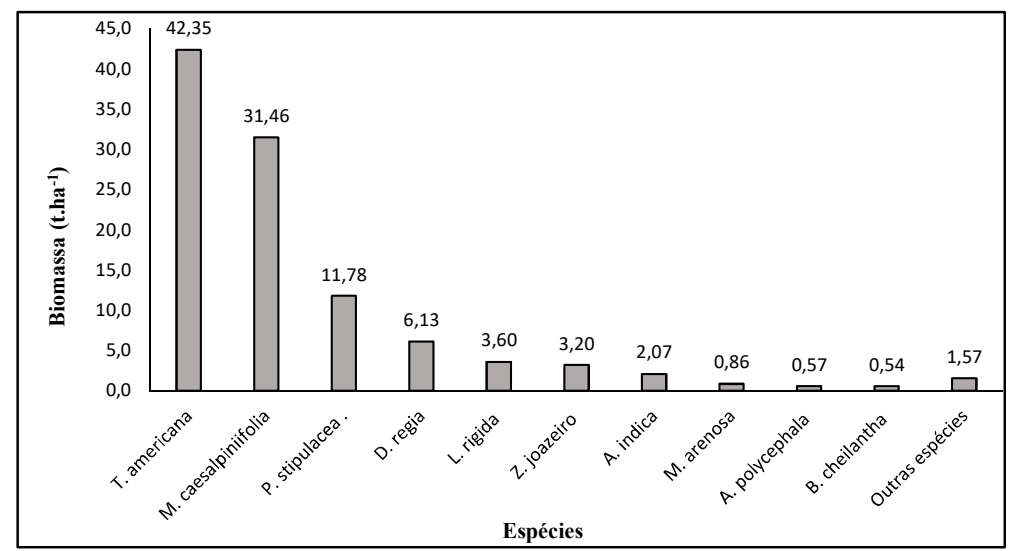

Figura 5: Estoque de biomassa $\left(\mathrm{t}_{\text {.ha }}{ }^{-1}\right.$ ) das espécies observadas no estrato arbóreo/arbustivo no fragmento de Caatinga em regeneração em Redenção, Ceará, Brasil, 2015.

\section{DISCUSSÃO}

A família Fabaceae, que se destacou em relações as outras famílias no fragmento de Caatinga, é formada por um grupo numeroso de espécies de relevância econômica e ecológica que favorecem a fixação biológica de nitrogênio beneficiando o aproveitamento agrícola. As espécies dessa família são importantes porque possibilitam a fixação biológica do nitrogênio (FBN) no solo, processo que propicia o sucesso destas espécies em ambientes com baixos teores deste nutriente e podem favorecer a colonização da área por 
outras espécies que também se beneficiam da FBN. Queiroz (2009) destaca que as espécies da família Fabaceae são encontradas em praticamente todos os ambientes terrestres, justificando sua importância pela associação com bactérias fixadoras de nitrogênio.

Conforme Cleveland et al. (2010) em ecossistemas naturais a FBN é a principal forma de entrada do nitrogênio no solo. Neste sentido, Freitas et al. (2012) salientam que as espécies fixadoras de nitrogênio são estrategicamente utilizadas para manejo agrícola, como adubadoras, por produzirem elevadas quantidades de biomassa que pode ser incorporada ao solo, além disso, as fabaceas nativas, adaptadas às condições de altas temperaturas e baixa disponibilidade de água do semiárido, podem ser capazes de crescer e, potencialmente, fixar nitrogênio com vantagem sobre outras espécies.

Sobre a FBN, Brito et al. (2011) relatam que o sucesso na formação de uma simbiose funcional das fabaceas é dependente de muitos fatores não sequenciais, tais como: físicos, ambientais, nutricionais e biológicos. Freitas et al. (2012) informam, também, que as espécies da família Fabaceae podem possuir potenciais como plantas forrageiras para a alimentação animal, por seus elevados valores nutritivo e rápida produção de biomassa.

A Piptadenia stipulacea que teve maior destaque entre as espécies da família Fabaceae na área de Caatinga na FEP, é popularmente conhecida como jurema branca, é encontrada na Caatinga, do estado do Piauí até a Bahia, possui altura com cerca de 2 a 4 m, casca castanho-claro e acúleos vigorosos (BRAGA, 1976). O fruto é em forma de vagem de cor castanho-pálido, com 8 a $12 \mathrm{~cm}$ de comprimento, com duas a doze sementes por vargem (FERREIRA et al., 2012). O comportamento de $P$. stipulacea reflete nitidamente os efeitos das perturbações a que uma vegetação foi submetida, mostrando-se bastante tolerante a elevados níveis de perturbação (PEREIRA et al., 2001), como por exemplo, áreas sob Caatinga em regeneração.

Santos et al. (2017) estudando a florística, a fitossociológia e o potencial madeireiro em área de Caatinga submetida a manejo florestal, constaram que as famílias Fabaceae e Euphorbiaceae foram as mais representativas em número de indivíduos, com total de 4.450 indivíduos.haำ, enquanto que no presente estudo estas duas famílias totalizaram uma densidade equivalente 1.902 indivíduos.ha $^{-1}$, representando $72 \%$ da densidade absoluta total da área. Estas duas famílias (Fabaceae e Euphorbiaceae) são as mais representativas em estudo sobre vegetação de Caatinga realizado por Pereira Junior et al. (2012), indicando que estas áreas estão em processo de recuperação, uma vez que estas espécies são consideradas de recomposição por comumente dominarem os primeiros estágios de sucessão.

A quantidade de espécies amostradas neste trabalho foi superior ao observado por Santos et al. (2017), que registraram 10 famílias, 18 gêneros e 21 espécies florestais na análise florística em área de Caatinga submetida a manejo florestal. Também por Santana et al. (2006) que, ao amostrarem uma área sem intervenções na Estação Ecológica do Seridó, constataram a presença de 22 espécies, 20 gêneros e 12 famílias.

O número de indivíduos que um ambiente pode suportar está diretamente relacionado com a diversidade das condições locais e pode variar de acordo com a precipitação, o tipo de solo e a intensidade de impactos antrópicos que a área foi submetida (SILVA et al., 2012). Dessa forma, é provável que a 
diversidade de espécies presentes na área em estudo, bem como sua densidade de indivíduos, seja reflexo tanto das condições do local, quanto do manejo agrícola praticado anteriormente na área. Porém, seriam necessários estudos mais detalhados, incluindo levantamentos em áreas de maior tempo de sucessão, para melhor averiguar a dinâmica de reestabelecimento desta vegetação.

As espécies $P$. stipulacea, $M$. caesalpiniifolia, $M$. arenosa também se destacam como de maiores valores de importante (IVI) em estudo realizado por Santos et al. (2017), em diferentes áreas de Caatinga. A dominância destas espécies indica que a áreas está em processo de recuperação, uma vez que estas são consideradas de recomposição, e, dominando os primeiros estágios de sucessão secundária (BESSA et al., 2011). Bessa et al. (2011) destacam a elevada capacidade que estas espécies têm de se regenerar após sofrerem algum tipo de injúria causada por atividades antrópica.

Já a espécies $A$. indica, que apresenta os quartos maiores índices fitossociológicos, é uma exótica, de crescimento inicial rápido, que foi anteriormente introduzida em áreas da fazenda, como componente do manejo de plantas ornamentais. Por ser de fácil dispersão, a espécie tem se estabelecido em áreas nativas, a partir dos indivíduos introduzidos nas áreas manejadas. Por serem de rápido crescimento e bem adaptadas às condições edafoclimáticas locais, esta espécie apresenta maiores diâmetros e alturas, se sobressaindo em relação a algumas espécies nativas da Caatinga.

As repostas das classes de diâmetros ao nível do peito (DNP) dos indivíduos amostrados na FEP apresentam similaridades os encontrados por Sá (2002), que observou a classe de diâmetro de 3,7 cm com $60 \%$ dos indivíduos amostrados em um trecho de floresta de restinga sob regeneração natural, grande parte composta por espécies abundantes com média de 5,94 cm. De acordo com Mathes (1992), para as espécies pioneiras não há uma relação entre o diâmetro do tronco e a idade da planta, mas com o vigor dos indivíduos.

As classes de alturas dos indivíduos estudados no estrato arbóreo/arbustivo no fragmento de Caatinga da FEP mostraram-se próximos ao relatado por Sá (2002), que estudou sobre a florística e estrutura de um trecho de floresta de restinga sob regeneração natural, que observou, aos seis anos após corte raso com destocamento, vegetação com aspecto emaranhado, composta por trepadeiras, arbustos e árvores, com raros indivíduos atingindo entre 5 e $7 \mathrm{~m}$ de altura, sendo, 2,38 $\mathrm{m}$ a altura média e 7,50 $\mathrm{m}$ a altura máxima.

As biomassas observadas para as três espécies de maiores contribuições ( $T$. gardneriana, M. Caesalpiniifolia e $P$. stipulacea) foram superiores ao observado para espécie de maior quantidade de biomassa (Mimosa tenuiflora) registrada em estudos de Lima Júnior et al. (2014). Os valores de biomassa observados no presente estudo foram influenciados pelos diâmetros e número de indivíduos, sendo o maior valor observado em $T$. gardneriana proporcionado por seu maior diâmetro, enquanto as espécies M. Caesalpiniifolia e $P$. stipulacea se destacaram no estoque de biomassa devido aos maiores números de indivíduos.

A espécie Triplaris gardneriana é conhecida popularmente como Pajeú, observada em áreas de matas ciliares, apresentando alta dominância $(<50 \%)$ devido elevados valores de diâmetro. Na FEP, a mesma foi observada no extremo da área estudada, próximo a um riacho, e, por estar situada em uma área de preservação permanente (APP), não sofreu corte no desmatamento para cultivo da área (realizado a seis 
anos antes da realização do levantamento), apresentando-se com grande porte em relação as demais espécies observadas. Assim, esta espécie contribuiu significativamente para o estoque de biomassa arbórea presente no fragmento estudado.

A biomassa de origem florestal representa um potencial alternativo a ser utilizada como fonte de energia limpa e renovável (SOARES et al., 2006), podendo contribuir para suprir parte da grande demanda de energia em decorrência do crescimento populacional e da atividade industrial. Neste sentido, Oliveira et al. (2006), destacam que a vegetação da Caatinga é mais empregada como fonte energética na forma de lenha e carvão, além de ser utilizada como estaca para construção de cercas, tendo seu uso limitado para indústria por seu porte arbóreo/arbustivo com grande quantidade de ramificações e fustes tortuosos e retorcidos. Estas características tendem a se acentuarem, com a elevada pressão de uso destas áreas, sem o devido período de pousio, bem como, a não adoção de adequados planos de manejo florestal. Porém, o porte e a biomassa observado na espécie Triplaris gardneriana neste estudo, mostram o potencial produtivo de áreas de Caatinga, que, com o manejo adequado poderá suprir parte da demanda energética brasileira, uma vez que a biomassa de origem florestal é uma importante fonte de energia na matriz energética do País (SIMIONI et al., 2018).

Por outro lado, destaca-se que a biomassa estocada nas árvores representa um importante reservatório de carbono, que permanecerá, por longos períodos, sequestrado no ecossistema terrestre, evitando assim emissões de gases de efeito estufa. Neste sentido, Aguiar et al. (2014) enfatizam que a vegetação arbórea é responsável pela maior parte do $C$ estocado no ecossistema de caatinga, sendo este compartimento um dos maiores sumidores terrestre de C.

\section{CONCLUSÕES}

O estudo apresenta a família Fabaceae com maior quantidade de indivíduos amostrados. As espécies a Piptadenia stipulacea, Mimosa caesalpiniifolia e Bauhinia cheilantha se destacam em maiores parâmetros fitossociológicos, além de mostrarem maior número de indivíduos e maiores valores de importância da área de Caatinga em regeneração.

As espécies presentes no fragmento de Caatinga em regeneração, notadamente T. gardneriana, M. Caesalpiniifolia e $P$. stipulacea, apresentam grande potencial para produção de biomassa, representando possíveis alternativas a serem utilizadas como fonte de energia renovável.

Três espécies ( $T$. gardneriana, M. Caesalpiniifolia e $P$. stipulacea) são as responsáveis pela maior parte da produção de biomassa do fragmento de Caatinga, representando possíveis alternativas a serem utilizadas como fonte de energia.

\section{REFERÊNCIAS}

AGUIAR, M. I.; FIALHO, J. S.; CAMPANHA, M. M.; OLIVEIRA T. S.. Carbon sequestration and nutrient reserves under different land use systems. Revista Árvore, v.38, p.81-93, 2014. DOI: https://doi.org/10.1590/S010067622014000100008
AMORIM, I. L.; SAMPAIO, E. V. S. B.; ARAÚJO, E. L.. Flora e estrutura da vegetação arbustivo-arbórea de uma área de caatinga do Seridó, RN, Brasil. Acta Botânica Brasílica, v.19, n.3, p.615-623. 2005. 
APG. The Angiosperm Phylogeny Group. An update of the Angiosperm phylogeny group classification for the orders and families of flowering plants: APG III. Botanical Journal of the Linnean Society, v.161, p.105-121, 2009. DOI: http://dx.doi.org/10.1111/j.1095-8339.2009.00996.x

BESSA, M. A. P.; MEDEIROS, J. F.. Levantamento florístico e fitossociológico em fragmentos de Caatinga no Município de Taboleiro Grande-RN. Geotemas, v.1, n.2, p.69-83, 2011.

BRAGA, R.. Plantas do Nordeste, especialmente do Ceará. 3 ed. Fortaleza: ESAM, 1976.

BRAND, M. A.. Potencial de uso da biomassa florestal da caatinga, sob manejo sustentável, para geração de energia. Ciência Florestal, v.27, n.1, p.117-127, 2017.

BRITO, M. M. P.; MURAOKA, T.; SILVA, E. C.. Contribuição da fixação biológica de nitrogênio, fertilizante nitrogenado e nitrogênio do solo no desenvolvimento de feijão e caupi. Bragantia, v.70, n.1, p.206-215, 2011.

CAMPOS, D. A.. Variabilidade temporal da biomassa florestal em fragmento de caatinga em regeneração a $\mathbf{4 0}$ anos. Monografia (Bacharel em Agronomia) - Universidade Federal do Ceará, Fortaleza, 2016.

CAVALCANTI, A. D. C.; RODAL, M. J. N.; SAMPAIO, E. V. S. B.; COSTA, K. C. C.. Mudanças florísticas e estruturais, após cinco anos, em uma comunidade de Caatinga no estado de Pernambuco, Brasil. Acta Botânica Brasílica, São Paulo, v.23, n.4, p.1210-1212, 2009.

CLEVELAND, C. C.; HOULTON, B. Z.; NEILL, C.; REED, S. C.; TOWNSEND, A. R.; WANG, Y.. Using indirect methods to constrain symbiotic nitrogen fixation rates: a case study from an Amazonian rain forest. Biogeochemistry, v.99, p.113, 2010.

COTTAM, G.; CURTIS, J. T.. The use of distance measures in phytosociological sampling. Ecology, v.37, p.451-460, 1956.

CORDEIRO, J. M. P.; FÉLIX, L. P.. Levantamento fitossociológico em mata de encosta no agreste paraibano. Geoambiente, Jataí, n.21, p.13-28, 2013.

FELFILI, J. A.; EISENLOHR, P. V.; MELO, M. M. R. F.; ANDRADE, L. A.; MEIRE NETO, J. A. A.. Fitossociologia no Brasil: Métodos e estudos de casos. UFV, 2011.

FERREIRA, W. N.; ZANDAVALLI, R. B.; BEZERRA, A. M. E.; MEDEIROS FILHO, S.. Crescimento inicial de Piptadenia stipulacea (Benth.) Ducke (Mimosaceae) e Anadenanthera colubrina (Vell.) Brenan var. cebil (Griseb.) Altshul (Mimosaceae) sob diferentes níveis de sombreamento. Acta Botânica Brasílica, v.26, n.2, p.408-414, 2012.

FREITAS, W. K.; MAGALHÃES, L. M. S.. Métodos e Parâmetros para Estudo da Vegetação com Ênfase no Estrato Arbóreo. Floresta e Ambiente, Rio de Janeiro, v.19, p.520-540, 2012.

FREITAS, A. D. S.; SAMPAIO, E. V. S.; ROSÁLIA, C. E.; SANTOS, S.; SILVA, A. F.; SOUZA, R. J. C.. Nodulação e fixação de nitrogênio por forrageiras da caatinga cultivadas em solos do semiárido paraibano. Revista Brasileira de Zootecnia, v.40, n.9, p.1856-1861, 2011.

HIGA, R. C. V.; CARDOSO, D. J.; ANDRADE, G. C.; ZANATTA, J. A.; ROSSI, L. M. B.; PULROLNIK, K.; NICODEMO, M. L. F.; GARRASTAZU, M. C.; VASCONCELOS, S. S.; SALIS, S. M.. Protocolo de medição e estimativa de biomassa e carbono florestal. Colombo: Embrapa Florestas, 2014.

IPECE. Instituto de Pesquisa e Estratégia Econômica do Ceará. Perfil básico do município Redenção. Fortaleza: IPECE, 2017.

LIMA JÚNIOR, C.; ACCIOLY, L. J. O.; GIONGO, V.; LIMA, R. L. F. A.; SAMPAIO, E. V. S. B.; MENEZES, R. S. C.. Estimativa de biomassa lenhosa da caatinga com uso de equações alométricas e índice de vegetação. Scientia Forestalis, Piracicaba, v.42, n.102, p.289-298, 2014.

MATHES, L. A. F.. Dinâmica da sucessão secundária em Mata, após ocorrência de fogo-Santa Genebra-Campinas, São Paulo. Tese (Doutorado) - Universidade Estadual de Campinas, Campinas, 1992

OLIVEIRA, E.; VITAL, V. R.; PIMENTA, A. S.; LUCIA, R. M. D.; LADEIRA, A. M. M.; CARNEIRO, A. C. O.. Estrutura Anatômica da Madeira e Qualidade do Carvão de Mimosa tenuiflora (Willd.) Poir. Revista Árvore, Viçosa, v.30, n.2, p.311-318, 2006.

PALÁCIO, H. A. Q.. Avaliação emergética de microbacias hidrográficas do semiárido submetidas a diferentes manejos. Tese (Doutorado em Engenharia Agrícola) Universidade Federal do Ceará, Fortaleza, 2011.

PEREIRA, I. M.; ANDRADE, L. A.; COSTA, J. R. M.; DIAS, J. M.. Regeneração natural em um remanescente de caatinga sob diferentes níveis de perturbação, no agreste paraibano. Acta Botânica Brasílica, v.53, n.3, p.413-426, 2001.

PEREIRA JÚNIOR, L. R. P.; ANDRADE, E. M.; PALÁCIO, H. A. Q.; RAYMER, P. C. L.; RIBEIRO FILHO, J. C.; PEREIRA, F. J. S. Carbon stocks in a tropical dry forest in Brazil. Revista Ciência Agronômica, v.47, n.1, p.32-40, 2016.

QUEIROZ, L. P.. Leguminosas da Caatinga. Feira de Santana: UEFS, 2009

RODAL, M. J. N.; SAMPAIO, E. V. S. B.; FIGUEIREDO, M. A.. Manual sobre métodos de estudos florístico $e$ fitossiciológico: ecossistema caatinga. Brasília: SB, 2013.

SÁ, C. F. C.. Regeneração de um trecho de floresta de restinga na Reserva Ecológica Estadual de Jacarepiá, Saquarema, Estado do Rio de Janeiro: II - Estrato arbustivo. Rodriguésia, v.53, n.82, p.5-23, 2002.

SANTANA, J. A. S.; SOUTO, J. S.. Diversidade e Estrutura Fitossociológica da Caatinga na Estação Ecológica do SeridóRN. Revista de Biologia e Ciências da Terra, São Cristóvão, v.6, n.2, p.232-242, 2006

SANTOS, W. S.; HENRIQUES, I. G. N.; SANTOS, W. S.; RAMOS, G. G.; VASCONCELOS, G. S.; VASCONCELO, A. D. M.. Análise florística-fitossociológica e potencial madeireiro em área de caatinga submetida a manejo florestal. Agropecuária Científica no Semiárido (ACSA), v.13, n.3, p.203-211, 2017. 
SOARES, T. S.; CARNEIRO, A. C. O.; GONÇALVES, E. O.; LELLES, J. G.. Uso da biomassa florestal na geração de energia. Revista Científica Eletrônica de Engenharia Florestal, n.8, p.1-9, 2006

SILVA, G. C.; SAMPAIO, E. V. S. B.. Biomassas de partes aéreas em plantas da Caatinga. Revista Árvore, n.32, p.567575, 2008.

SILVA, B. L. R.; TAVARES, F. M.; CORTEZ, J. S. A.. Composição florística do componente herbáceo de uma área de caatinga
- Fazenda Tamanduá, Paraíba, Brasil. Revista de Geografia, v.29, n.3, 2012.

SIMIONI, F. J.; BUSCHINELLI, C. C. A.; DEBONI, T. L.; PASSOS, B. M.. Cadeia produtiva de energia de biomassa florestal: o caso da lenha de eucalipto no polo produtivo de Itapeva, SP. Ciência Florestal, v.28, n.1, p.310-323, 2018.

VELAZCO, S. J. E.; GALVÃO, F.; KELLER, H. A.; BEDRIJ, N. A.. Florística e fitossociologia de uma floresta estacional semidecidual, reserva privada Osununú-Misiones, Argentina. Floresta e Ambiente, v.22, n.1, p.1-12, 2015.

A CBPC - Companhia Brasileira de Produção Científica (CNPJ: 11.221.422/0001-03) detém os direitos materiais desta publicação. Os direitos referem-se à publicação do trabalho em qualquer parte do mundo, incluindo os direitos às renovações, expansões e disseminações da contribuição, bem como outros direitos subsidiários. Todos os trabalhos publicados eletronicamente poderão posteriormente ser publicados em coletâneas impressas sob coordenação da Sustenere Publishing, da Companhia Brasileira de Produção Científica e seus parceiros autorizados. Os (as) autores (as) preservam os direitos autorais, mas não têm permissão para a publicação da contribuição em outro meio, impresso ou digital, em português ou em tradução. 